\title{
A Comparative Study on Equilibrium Adsorption of Dyes on Adsorbents Prepared from Coastal Plant, C. equisetifolia Seeds via Green Modification and Activated Carbon
}

\author{
Jazulhafiz Jefri Jaafar ${ }^{1}$, Mohamad Awang ${ }^{1, \text { a }}$, Anis Ayuni Aman Zuki ${ }^{1}$, Mohammad Hussin Zain ${ }^{2}$, Asmadi Ali @ Mahmud ${ }^{1}$ \\ ${ }^{1}$ School of Ocean Engineering, Universiti Malaysia Terengganu, 21030 Kuala Terengganu, Terengganu, Malaysia \\ ${ }^{2}$ School of Fundamental and Liberal Studies, Universiti Malaysia Terengganu, 21030 Kuala Terengganu, Terengganu, Malaysia
}

\begin{abstract}
Eco-friendly adsorbents were prepared from coastal plant, $C$. equisetifolia seeds treated with $\beta$-cyclodextrin (Rhusorbent) for the removal of dyes. The study was carried out to determine the effectiveness of Rhusorbent to remove common dyes such as malachite green (MG) and neutral red (NR) dyes from aqueous solutions in batch experiments. The commercial activated carbon (AC) was also used in this equilibrium absorption study which includes the effect of adsorbent dosage, initial dye concentration and contact time. The percentage of MG dye removal of about $92.4 \%$ and $88.4 \%$ was achieved for both Rhusorbent and AC respectively at concentration of $60 \mathrm{mg} / \mathrm{L}$ and $0.4 \mathrm{~g}$ absorbent. The equilibrium adsorption of about $91.1 \%$ and $79.1 \%$ was achieved for both Rhusorbent and AC respectively involving NR dye. The scanning electron micrographs of Rhusorbent show uneven and rough surface prompting evidence for the effective adsorption of MG and NR dyes on the surface of adsorbents. For both adsorption studies, Langmuir and Freundlich isotherm models fitted well the adsorption data involving both Rhusorbent and AC. C. equisetifolia seeds are a potential source for bio-inspired adsorbents for the removal of MG and NR dyes.
\end{abstract}

\section{Introduction}

Water has become increasingly important for both agricultural and industrial sectors as well as for daily use. But today, the point and non-point sources of water pollution are contaminating our valuable water resources. Water pollution is a global problem that has led to interests in pollution control. On the positive side, dyes can give beautiful color to various products, and therefore they are widely used in many fields such as textiles, paper, plastic, food, painting, and medicine [1]. However, the release of effluent dyes into the ecosystem is a dramatic source of aesthetic pollution and of perturbations in aquatic life. Most synthetic dyes are toxic and can bring about serious water pollution, destroy community structure of aquatic organisms, and further become a hazard to all mankind. Since the removal of dyes from wastewater is considered an environmental challenge and government legislation requires textile wastewater to be treated, therefore there is a constant need to have an effective process that can efficiently remove these dyes [2].

Adsorption being a physical process, in-expensive and less time consuming, is widely accepted [3]. Adsorption onto activated carbon is widely practiced for removal of dissolved dyes from wastewater. However, adsorbentgrade activated carbon is cost-prohibitive. So it is necessary to seek some alternative low-cost adsorbents to activated carbon. The plant waste from C. equisetifolia plant seeds has been chosen as an adsorbent due to its vast availability since its seeds is abundant in nature, plus the fact that it is non-toxic, environmental friendly, biodegradable and cheap raw materials.

\section{Methodology}

\subsection{Preparation of Adsorbent}

C. equisetifolia plant seeds were washed with distilled water to eliminate dust, sand impurities and other unwanted chemicals. Then, the seeds were dried in an oven at the temperature of $70^{\circ} \mathrm{C}$ for a period of 24 hours. The seeds were ground with a crusher and sieved into small particles with an average size ranging between 2.0 and $3.0 \mathrm{~mm}$. Then ground seeds were treated with $0.01 \mathrm{M}$ $\beta$-cyclodextrin for 24 hour. Then the $\beta$-cyclodextrintreated seeds were washed with water and dried in oven at temperature of $70{ }^{\circ} \mathrm{C}$ for a period of 24 hours to produce Rhusorbent. Activated carbon (AC) with similar size range was heated at $70{ }^{\circ} \mathrm{C}$ for 5 hours prior to adsorption test. Surface morphology of RhuSorbent and AC was investigated using scanning electron microscope.

\subsection{Batch Adsorption Studies}

\footnotetext{
$\overline{{ }^{a} \text { Corresponding author: mohamada } @ u m t . e d u . m y ~}$
} 
In each batch, adsorption test was carried out in a $250 \mathrm{ml}$ conical flask in which the MG and NR dyes initial concentrations were fixed at $100 \mathrm{ml}$ with different concentrations. After that, Rhusorbent of $0.4 \mathrm{~g}$ was added into the solution. The effect of contact time on the adsorption process was examined.

The mixed solution was stirred on the rotary shaker at rotation speed of $250 \mathrm{rpm}$ at the room temperature. Then, the residual concentration was determined using absorbance values measured before and after the adsorption by UV-Visible spectrophotometer (UV-Vis) at wavelength of the dye solutions. UV-Vis scans were taken at 30, 60, 90, 120, 150, 180, 210 and $240 \mathrm{~min}$. The $\mathrm{MG}$ and NR dyes removal percentage was calculated based on the following equation:

Dye Removal $\%=\left(\mathrm{C}_{0}-\mathrm{C}_{\mathrm{i}}\right) / \mathrm{C}_{0} \times 100$

where, $\mathrm{C}_{0}$ and $\mathrm{Ci}(\mathrm{mg} / \mathrm{L})$ are the initial and final dye concentrations respectively. The average dye removal percentage was calculated based on three replicates.

\section{Results and Discussion}

\subsection{Morphological characterization of adsorbent}

Figs. 1(a) and 1(b) show the scanning electron micrographs of Rhusorbent and AC. While the surface morphology of the AC does show rough surface, the micrograph of Rhusorbent also indicates rough surface and caves-like and more uneven surface. The presence of rough and irregular surfaces of $\beta$-cyclodextrin-treated Rhusorbent in this case may be associated with the breaking of the covalent bond and the hydroxyl group present in the cellulose or lignin of fibers [4]. The rough surface may also be formed due to the removal of hemicelluloses, lignin and cellulosic constituents after treatment $[5,6]$. As a result, more reactive hydroxyl group exposed on the fibers surface contributing to rough surface. The presence of cracks on the plant seed surface may be due to the reaction between acetyl groups with the fibers hydroxyl groups and thus the molecular orientation of the cellulose backbone was changed. As a result, the fiber becomes rougher and stiffer in character. This reduces the hydrophilicity of the fiber [7].

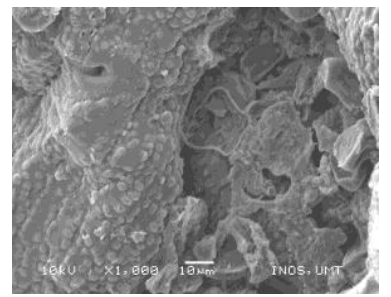

(a)

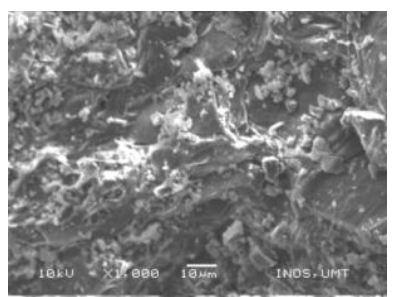

(b)
Figure 1. Morphology of (a) Rhusorbent and (b) activated carbon

\subsection{Batch Adsorption Studies}

Table 1 and Table 2 show the percentage of MG dye removal at different initial dye concentrations for Rhusorbent and AC. The equilibrium adsorption of MG onto both Rhusorbent and AC was achieved within 240 min at various initial MG dye concentrations. Table 3 and 4 are the results of NR dye removal at different initial dye concentration versus time shows a similar trend to that of MG dye removal. Both percentage of MG and NR dyes removal decreased as the initial dye concentration increased as higher dye concentration lowers adsorption due to the saturation of adsorption sites.

Table 1. Percentage of MG removal for Rhusorbent treated with $\beta$-cyclodextrin

\begin{tabular}{|c|c|c|c|c|c|}
\hline \multirow{2}{*}{$\begin{array}{c}\text { Time } \\
(\mathrm{min})\end{array}$} & \multicolumn{5}{|c|}{ Percentage of MG Removal (\%) } \\
\cline { 2 - 6 } & $\begin{array}{c}60 \\
\mathrm{mg} / \mathrm{L}\end{array}$ & $\begin{array}{c}100 \\
\mathrm{mg} / \mathrm{L}\end{array}$ & $\begin{array}{c}200 \\
\mathrm{mg} / \mathrm{L}\end{array}$ & $\begin{array}{c}300 \\
\mathrm{mg} / \mathrm{L}\end{array}$ & $\begin{array}{c}400 \\
\mathrm{mg} / \mathrm{L}\end{array}$ \\
\hline 30 & 56.62 & 53.44 & 21.29 & 20.90 & 21.13 \\
60 & 68.21 & 55.11 & 27.08 & 22.01 & 28.53 \\
90 & 71.39 & 58.08 & 33.43 & 22.92 & 33.29 \\
120 & 76.15 & 68.99 & 39.70 & 24.70 & 33.80 \\
150 & 79.47 & 72.42 & 53.66 & 38.43 & 34.39 \\
180 & 89.09 & 80.63 & 69.27 & 41.69 & 34.82 \\
210 & 91.41 & 84.99 & 69.82 & 42.93 & 34.98 \\
240 & 92.39 & 85.58 & 70.29 & 43.91 & 35.57 \\
\hline
\end{tabular}

Table 2. Percentage of MG removal for activated carbon

\begin{tabular}{|c|c|c|c|c|c|}
\hline \multirow{2}{*}{$\begin{array}{c}\text { Time } \\
(\mathrm{min})\end{array}$} & $\begin{array}{c}60 \\
\mathrm{mg} / \mathrm{L}\end{array}$ & $\begin{array}{c}100 \\
\mathrm{mg} / \mathrm{L}\end{array}$ & $\begin{array}{c}200 \\
\mathrm{mg} / \mathrm{L}\end{array}$ & $\begin{array}{c}300 \\
\mathrm{mg} / \mathrm{L}\end{array}$ & $\begin{array}{c}400 \\
\mathrm{mg} / \mathrm{L}\end{array}$ \\
\cline { 2 - 6 } & 64.26 & 66.44 & 28.96 & 26.96 & 13.61 \\
60 & 72.72 & 67.46 & 24.31 & 30.48 & 14.08 \\
90 & 75.78 & 78.31 & 39.44 & 30.97 & 16.42 \\
120 & 77.79 & 82.36 & 45.52 & 41.63 & 19.11 \\
150 & 83.56 & 86.41 & 54.42 & 45.37 & 19.91 \\
180 & 85.27 & 85.91 & 71.59 & 45.18 & 20.09 \\
210 & 87.62 & 86.16 & 73.13 & 45.35 & 19.96 \\
240 & 88.38 & 86.59 & 73.29 & 45.09 & 20.03 \\
\hline
\end{tabular}

Table 3. Percentage of NR removal for Rhusorbent treated with $\beta$-cyclodextrin

\begin{tabular}{|c|c|c|c|c|c|}
\hline \multirow{2}{*}{$\begin{array}{l}\text { Time } \\
\text { (min) }\end{array}$} & \multicolumn{5}{|c|}{ Percentage of NR Removal (\%) } \\
\hline & $\begin{array}{c}60 \\
\mathrm{mg} / \mathrm{L}\end{array}$ & $\begin{array}{c}100 \\
\mathrm{mg} / \mathrm{L}\end{array}$ & $\begin{array}{c}200 \\
\mathrm{mg} / \mathrm{L}\end{array}$ & $\begin{array}{c}300 \\
\mathrm{mg} / \mathrm{L}\end{array}$ & $\begin{array}{c}400 \\
\mathrm{mg} / \mathrm{L}\end{array}$ \\
\hline 30 & 51.18 & 37.45 & 20.56 & 20.90 & 19.26 \\
\hline 60 & 64.00 & 45.82 & 24.42 & 22.01 & 23.11 \\
\hline 90 & 81.76 & 72.19 & 30.41 & 22.92 & 27.08 \\
\hline 120 & 88.81 & 83.27 & 35.28 & 24.70 & 29.64 \\
\hline 150 & 90.29 & 85.48 & 38.29 & 38.43 & 31.55 \\
\hline 180 & 90.31 & 85.51 & 41.81 & 41.69 & 35.94 \\
\hline 210 & 90.79 & 86.23 & 42.47 & 42.93 & 36.54 \\
\hline 240 & 91.10 & 86.69 & 42.67 & 43.91 & 37.09 \\
\hline
\end{tabular}

At the lowest initial dye concentration $(60 \mathrm{mg} / \mathrm{L})$, it is observed that the percentage of MG dye removal for Rhusorbent and $\mathrm{AC}$ at $240 \mathrm{~min}$ was about $92.4 \%$ and $88.4 \%$ respectively. At the highest initial dye concentration $(400 \mathrm{mg} / \mathrm{L})$, the percentage of $\mathrm{MG}$ dye 
removal using Rhusorbent at 240 min was higher than that of AC. The equilibrium adsorption of $\mathrm{MG}$ dye for Rhusorbent and $\mathrm{AC}$ was $35.6 \%$ and $20.0 \%$ respectively. The removal percentage of NR dye using RhuSorbent was better that that of $\mathrm{AC}$ at all initial dye concentrations. At the lowest initial dye concentration $(60 \mathrm{mg} / \mathrm{L})$, the percentage of NR dye removal using Rhusorbent and AC at $240 \mathrm{~min}$ was $91.1 \%$ and $79.1 \%$ respectively. Meanwhile, at the highest initial dye concentration (400 $\mathrm{mg} / \mathrm{L}$ ), the percentage of NR dye removal using Rhusorbent and $\mathrm{AC}$ at $240 \mathrm{~min}$ was $37.1 \%$ and $24.6 \%$, respectively. The adsorption for both MG and NR dyes at different dye concentrations was rapid at the initial stages and gradually decreased with the progress of adsorption until the equilibrium was reached.

Table 4. Percentage of NR removal for activated carbon

\begin{tabular}{|c|c|c|c|c|c|}
\hline \multirow{2}{*}{$\begin{array}{c}\text { Time } \\
(\mathrm{min})\end{array}$} & \multicolumn{5}{|c|}{ Percentage of NR Removal (\%) } \\
\cline { 2 - 6 } & $\begin{array}{c}60 \\
\mathrm{mg} / \mathrm{L}\end{array}$ & $\begin{array}{c}100 \\
\mathrm{mg} / \mathrm{L}\end{array}$ & $\begin{array}{c}200 \\
\mathrm{mg} / \mathrm{L}\end{array}$ & $\begin{array}{c}300 \\
\mathrm{mg} / \mathrm{L}\end{array}$ & $\begin{array}{c}400 \\
\mathrm{mg} / \mathrm{L}\end{array}$ \\
\hline 30 & 47.02 & 36.44 & 15.34 & 16.15 & 13.16 \\
60 & 53.65 & 42.10 & 22.31 & 19.86 & 14.17 \\
90 & 63.1 & 45.95 & 26.11 & 26.16 & 15.60 \\
120 & 77.39 & 58.37 & 26.36 & 28.83 & 17.10 \\
150 & 83.56 & 66.47 & 30.2 & 31.03 & 19.69 \\
180 & 78.34 & 77.14 & 34.87 & 32.82 & 21.69 \\
210 & 79.36 & 76.30 & 35.49 & 33.26 & 24.17 \\
240 & 79.11 & 77.24 & 36.13 & 33.36 & 24.60 \\
\hline
\end{tabular}

\subsection{Adsorption Isotherm}

\subsubsection{Langmuir model}

The Langmuir equation has been applied for the monolayer sorption onto a surface of a finite number of identical sites with negligible interaction between of molecule [8]. It is also observed that the initial removal of dye is fast and with the rise in concentration the percentage uptake gradually decreases. The form of the Langmuir isotherm can be represented by the following equation:

$$
q_{e}=q_{m}\left[\left(\mathrm{~K}_{\mathrm{L}} \mathrm{C}\right) /\left(1+\mathrm{K}_{\mathrm{L}} \mathrm{Ce}\right)\right]
$$

where $q_{e}$ was the amount of dye adsorbed per gram of adsorbent (mg/g), C denotes the equilibrium concentration of dye in solution $(\mathrm{mg} / \mathrm{L}) ; \mathrm{K}_{\mathrm{L}}$ represents the Langmuir constant $(\mathrm{L} / \mathrm{mg})$ that related to the affinity of binding sites and $\mathrm{q}_{\mathrm{m}}$ was a theoretical limiting adsorption capacity when the monolayer surface was fully covered with dye molecules and assists in the comparison of adsorption performance $(\mathrm{mg} / \mathrm{g})$. Linear plots obtained for $1 / q_{e}$ against $1 / \mathrm{C}_{\mathrm{e}}$ with $\mathrm{R}^{2}$ values in Figures 2 and 3 indicate that the Langmuir isotherm holds good for the MG-Rhusorbent and NR-Rhusorbent systems.

\subsubsection{Freundlich model}

The Freundlich isotherm model is based on the assumption that adsorption occurs on the heterogeneous adsorption surface having unequally available sites with different energies of adsorption [9]. The Freundlich isotherms model had the following form:

$$
\mathrm{q}_{\mathrm{e}}=\mathrm{K}_{\mathrm{F}} \mathrm{C}_{1} / \mathrm{n}
$$

where $\mathrm{q}_{\mathrm{e}}$ was the amount of dyes adsorbed per gram of adsorbent (mg/g); $\mathrm{C}$ was the equilibrium dye concentration in solution $(\mathrm{mg} / \mathrm{L}) ; \mathrm{K}_{\mathrm{F}}$ and $\mathrm{n}$ were the Freundlich constants, which represented the adsorption capacity and the adsorption strength, respectively. The magnitude of $1 / \mathrm{n}$ quantified the favorability of adsorption and the degree of heterogeneity of the adsorbent surface [6].

The Freundlich isotherm is represented by equation:

$$
\log \mathrm{q}_{\mathrm{e}}=\log \mathrm{K}_{\mathrm{F}}+1 / \mathrm{n} \log \mathrm{C}
$$

The Freundlich adsorption isotherm plot is made between $\log \mathrm{C}_{\mathrm{e}}$ and $\log \mathrm{q}_{\mathrm{e}}$ as shown in Figures 4 and 5 . The isotherm data for RhuSorbent fitted the Freundlich model with $0.99 \mathrm{R}^{2}$.

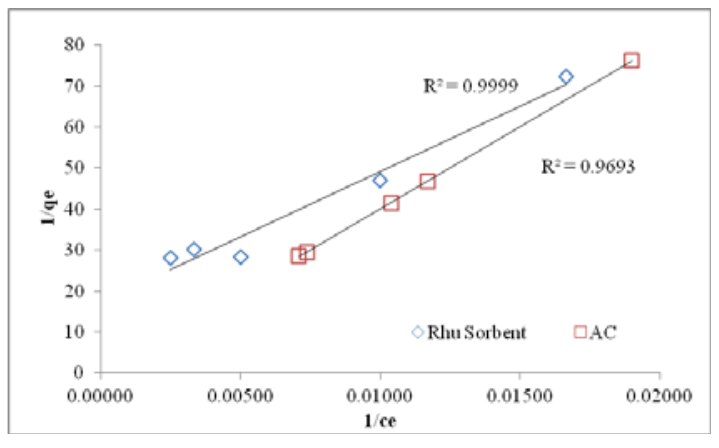

Figure 2. Langmuir isotherm for MG dye adsorption onto Rhusorbent and AC

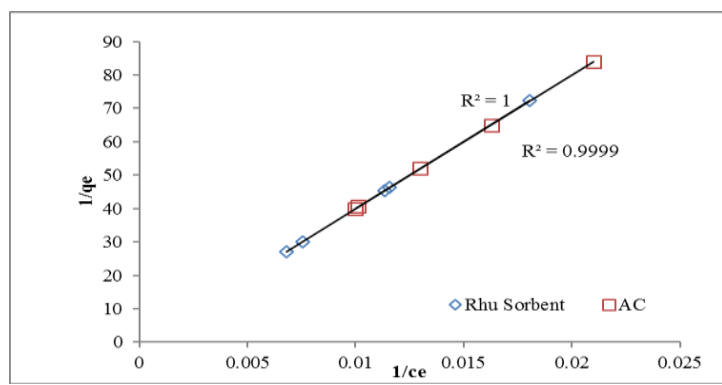

Figure 3. Langmuir isotherm for NR dye adsorption onto RhuSorbent treated and AC

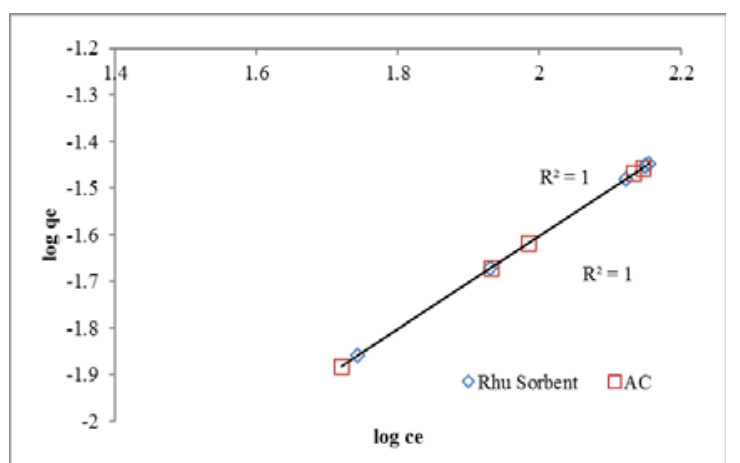

Figure 4. Freundlich isotherm for MG dye adsorption onto Rhusorbent treated and $\mathrm{AC}$ 


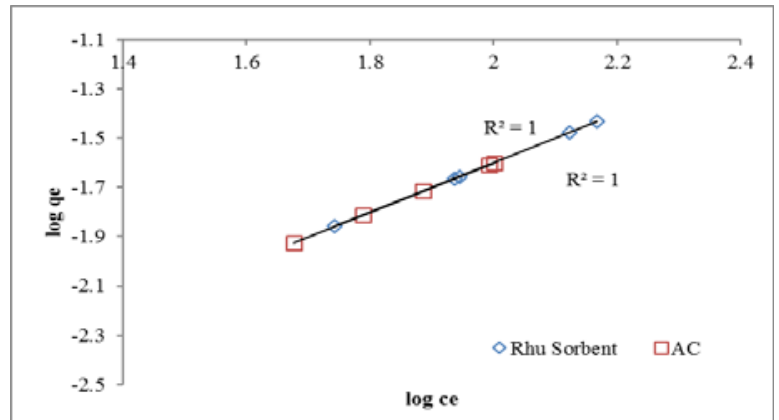

Figure 5. Freundlich isotherm for NR dye adsorption onto Rhusorbent treated and $\mathrm{AC}$

\section{Conclusions}

C. equisetifolia seeds are a potential source for bioinspired adsorbents for the removal of $\mathrm{MG}$ and $\mathrm{NR}$ dyes. The effectiveness of green modification of adsorbents prepared from $C$. equisetifolia seeds using $\beta$-cyclodextrin (Rhusorbent) in dye removal may add another ecofriendly adsorbent to the present list and hence protect the environment. The future works may include the kinetic study on the adsorption of the same dyes as well as the effectiveness of the green modification using other bioinspired adsorbents.

\section{Acknowledgement}

The authors wish to thank the Ministry of Higher Education Malaysia (VOT 59274) and the School of
Ocean Engineering, Universiti Malaysia Terengganu for the financial support.

\section{References}

1. J. Tan, X. Zhang, X. Wei, L. Wang, Bioresources 7, $3(2012)$

2. M.A. Mohd Salleh, D.K. Mahmoud, W.A. Wan Abdul Karim, A. Idris, Desalination 280 (2011)

3. N. Sharma, D.P. Tiwari, S.K. Singh, International Journal of Scientific \& Engineering Research 3, 2 (2012)

4. I.O. Bakare, F.E. Okiemen, C. Pavithran, H.P.S Abdul Khalil, M. Brahma Kumar, Material Design 3 (2010)

5. J. Rout, M. Misra, S.S. Triphathy, S.K. Nayak, A.K. Mohanty, Comp. Sci. and Tech. 61, 9 (2001)

6. E. Sinha, S.K. Rout, Bulletin of Materials Science 32, 1 (2009)

7. V.P. Cyras, C. Vallo, J.M. Kenny, A. Vasquez, Journal Composite Materials 38, 16 (2004)

8. T.C. Chandra, M.M. Mirna, Y. Sudaryanto, S. Ismadji, Chemicals Engineering Journal 127 (2007)

9. B.H. Hameed, D.K. Mahmoud, A.L. Ahmad, Journal of Hazardous Materials 158 (2008) 